Supporting information for

\title{
Copper speciation evolution in swine manure induced by pyrolysis
}

Yuan Cheng, ${ }^{1,2}$ Lei Luo, ${ }^{* 1}$ Jitao Lv, ${ }^{1}$ Gang Li, ${ }^{1}$ Bei Wen, ${ }^{1}$ Yibing Ma, ${ }^{3}$ and Rixiang Huang ${ }^{4}$

${ }^{1}$ State Key Laboratory of Environmental Chemistry and Ecotoxicology, Research Center for EcoEnvironmental Sciences, Chinese Academy of Sciences, Beijing 100085, China

${ }^{2}$ University of Chinese Academy of Sciences, Beijing 100049, China

${ }^{3}$ Institute of Agricultural Resources and Regional Planning, Chinese Academy of Agricultural Sciences, Beijing 100081, China

${ }^{4}$ Department of Environmental and Sustainable Engineering, University at Albany, State University of New York, 1400 Washington Avenue, Albany, New York, 12222

*Corresponding author. E-mail: leiluo@rcees.ac.cn

Journal: Environmental Science \& Technology

Content: 10 pages, 8 figures and 3 tables. 


\section{Supplemental Methods}

Total and available $\mathrm{Cu}$ determination. Total $\mathrm{Cu}$ content in the raw and pyrolyzed swine manure and feedstuff samples was digested with a concentrated HF-HNO3- $\mathrm{H}_{2} \mathrm{O}_{2}$ mixture $(1: 2: 1, \mathrm{v} / \mathrm{v} / \mathrm{v})$ using a Mars 6.0 microwave instrument, held constant at $210{ }^{\circ} \mathrm{C}$ for $60 \mathrm{~min}$, then cooled to below $100{ }^{\circ} \mathrm{C}$ and the gases vented (Meng et al., 2018). The digestion tubes were heated at $140{ }^{\circ} \mathrm{C}$ to dryness. The solutions were transferred, adjusted with distilled water to a final volume of $50 \mathrm{~mL}$. Available $\mathrm{Cu}$ in the samples were extracted with a mixture containing $0.005 \mathrm{~mol} / \mathrm{L}$ diethylenetriaminepentaacetic acid (DTPA), $0.01 \mathrm{~mol} / \mathrm{L} \mathrm{CaCl}_{2}$ and $0.1 \mathrm{~mol} / \mathrm{L}$ triethanolamine (pH 7.3) (Lindsay and Norvell, 1976; Meng et al., 2017). The suspensions (at a 1:5 ratio, w/v) were shaken at $120 \mathrm{rpm}$ on a thermostatic shaker for $2 \mathrm{~h}$ at $25^{\circ} \mathrm{C}$ before centrifuged. All these digestion solutions and extracts, conducted in triplicate, were analyzed using ICP-OES (Optima 2000DV, Perkin Elmer).

\section{Cu K-edge XAFS analysis}

Energy calibration used the $\mathrm{Cu}$ foil (at $8978.9 \mathrm{eV}$ ). Spectra of the reference foil were collected simultaneously with sample scans. Swine manure and feedstuff samples and derived biochars were ground into fine powders and packed into Teflon sample holders covered with Kapton tape. XAS data for these samples were collected in fluorescence mode at room temperature using a 32-element Ge solid-state detector. A large library of reference compounds was prepared and analyzed in transmission mode, which included $\mathrm{Cu}_{2} \mathrm{~S}, \mathrm{CuS}, \mathrm{Cu}(\mathrm{I})$-cysteine complex, $\mathrm{CuSO}_{4}, \mathrm{Cu}_{2} \mathrm{O}, \mathrm{CuO}, \mathrm{Cu}$ phosphate $\left(\mathrm{Cu}_{3}\left(\mathrm{PO}_{4}\right)_{2}\right), \mathrm{Cu}_{2}(\mathrm{OH})_{2} \mathrm{CO}_{3}$, and $\mathrm{Cu}(\mathrm{II})$ organic complex $\left(\mathrm{Cu}\left(\mathrm{CH}_{3} \mathrm{COO}\right)_{2}\right)$.

The XAS data were normalized and deconvoluted using the Athena software (Ravel and Newville, 2005) following the protocol as recommended by Werner and Prietzel (2015). Multiple scans (2-6) were energy calibrated and averaged for further analysis. Principal component analysis (PCA) was conducted on the normalized sample spectra to determine the number of components (i.e., reference spectra) needed for obtaining reasonable fits. PCA of both XANES and EXAFS spectra revealed that 4 components accounted for the majority of the variance for $\mathrm{Cu}$. Using the corresponding reference compound spectra library, target transformation (TT) was conducted to determine appropriate candidate compounds, and only standards with SPOIL values $<3$ in either the XANES or EXAFS TT procedure were included in the LCF (Donner et al., 2011). PCA and TT were undertaken using SixPack (Ravel and Newville, 2005). LCF was conducted on both XANES (-25 to 
$+100 \mathrm{eV})$ and EXAFS $\left(2.5-11.5 \AA^{-1}\right)$ regions to obtain the speciation compositions of $\mathrm{Cu}$ in the samples. Combinations of TT-determined candidate compounds were used, and the goodness of fit was determined by $\mathrm{R}$-factor. Fits with smallest $R$-factors were chosen as the most likely set of components.

It is necessary to note that as uncertainty in species apportionment is estimated to be approximately $10 \%$ of total amount of the target element, the proportion of the fractions less than $10 \%$ have a large uncertainty (Donner et al., 2011). In addition, it is well known that the LCF results are dependent on the choice of standards selected. Due to the highly heterogeneous nature of these samples, it is important not to overinterpret the LCF speciation results. For example, an indication of binding to $\mathrm{CH}_{3} \mathrm{COO}^{-}$does not necessarily demonstrate exclusive binding to that particular ligand but does strongly indicate complexation with organic moieties rather than a mineral surface (Donner et al., 2011).

\section{$S$ and $P$ K-edge XANES analyses.}

$\mathrm{S} K$-edge $(2472 \mathrm{eV})$ and $\mathrm{P} K$-edge $(2145 \mathrm{eV})$ XANES spectra of the raw swine manure and pyrolyzed samples and the relevant reference compounds were collected at beamline 4B7A of Beijing Synchrotron Radiation Facility. Spectra were recorded in the energy range 2450-2520 eV and 2129$2220 \mathrm{eV}$, respectively, in fluorescence mode by a silicon drift detector (e2v, Chelmsford, UK) for S and $\mathrm{P}$ speciation analyses. The energy was calibrated separately with the absorption maximum of $\mathrm{Na}_{2} \mathrm{SO}_{4}$ (at $2482.7 \mathrm{eV}$ ) and $\mathrm{AlPO}_{4}(2149 \mathrm{eV})$ after every five determinations on the samples to remove possible drift $(<0.1 \mathrm{eV})$. The pulverized soil samples were mounted thinly in 2.5- $\mu \mathrm{m}$ S-free Mylar film envelopes, and placed into a sample chamber purged with helium. Each XANES spectrum represents an average of three scans.

All data were baseline-corrected and edge-normalized. The contribution of different $\mathrm{S} / \mathrm{P}$ species to total S/P was deconvoluted over the 2466-2489 eV energy range by Gaussian curve fitting (Manceau \& Nagy, 2012; Luo et al., 2014) and over the 2140-2180 eV energy range (-15 to $+35 \mathrm{eV}$ relative to P $K$-edge) by LCF (Luo et al., 2017), respectively. $\mathrm{E}_{0}$ values of reference compounds were allowed to float up to $\pm 0.1 \mathrm{eV}$. XRD patterns revealed that struvite and brushite were presented in the swine manure (Figure S6), these phases were therefore selected as required standards for LCF. Because of the presence of high contents of available/exchangeable inorganic phosphate in the swine 
manure and derived biochars and the lack of distinctive XANES features between aqueous and adsorbed phosphate, aqueous phosphate was included as the fraction of "free and weakly bound (adsorbed) phosphates" (Sato et al., 2005) for LCF analysis. Therefore, P reference compounds include calcium phosphate dibasic $\left(\mathrm{CaHPO}_{4}\right)$, hydroxyapatite $\left(\mathrm{Ca}_{5}\left(\mathrm{PO}_{4}\right)_{3}(\mathrm{OH})\right), \mathrm{FePO}_{4}$, aluminum phosphate $\left(\mathrm{AlPO}_{4}\right)$, struvite $\left(\mathrm{MgNH}_{4} \mathrm{PO}_{4}\right)$, phytic acid, pyrophosphate $\left(\mathrm{Na}_{4} \mathrm{P}_{2} \mathrm{O}_{7}\right)$, soluble aqueous phosphate $\left(\mathrm{NaH}_{2} \mathrm{PO}_{4}\right)$ and $\mathrm{Cu}$ phosphate $\left(\mathrm{Cu}_{3}\left(\mathrm{PO}_{4}\right)_{2}\right)$ (Figure $\mathrm{S} 8$ ) were used for the principal component analysis, target transformation, and LCF analysis. Different positions of white line (i.e. the absorption peak at around $2152 \mathrm{eV}$ ) varied among Ca-P, Fe-P, soluble phosphate, and organic $\mathrm{P}$ (Brunn et al., 2017; Güngör et al., 2007; Luo et al., 2017) and the distinct (pre- or should) features of Ca-P, Fe-P, and Cu-P (Ingall et al., 2011) made it possible to identify the species composition of P in the swine manure and derived biochar. The goodness of fit was evaluated using the residual factor $(R$ factor), and the fit with the smallest $R$ factor was deemed the best fit. The coefficient of variation was less than $10 \%$ for each $\mathrm{S} / \mathrm{P}$ fraction in this study. More information on the $\mathrm{S}$ and $\mathrm{P} K$-edge XANES analyses can be found in Luo et al. (2014) and Luo et al. (2017), respectively. 


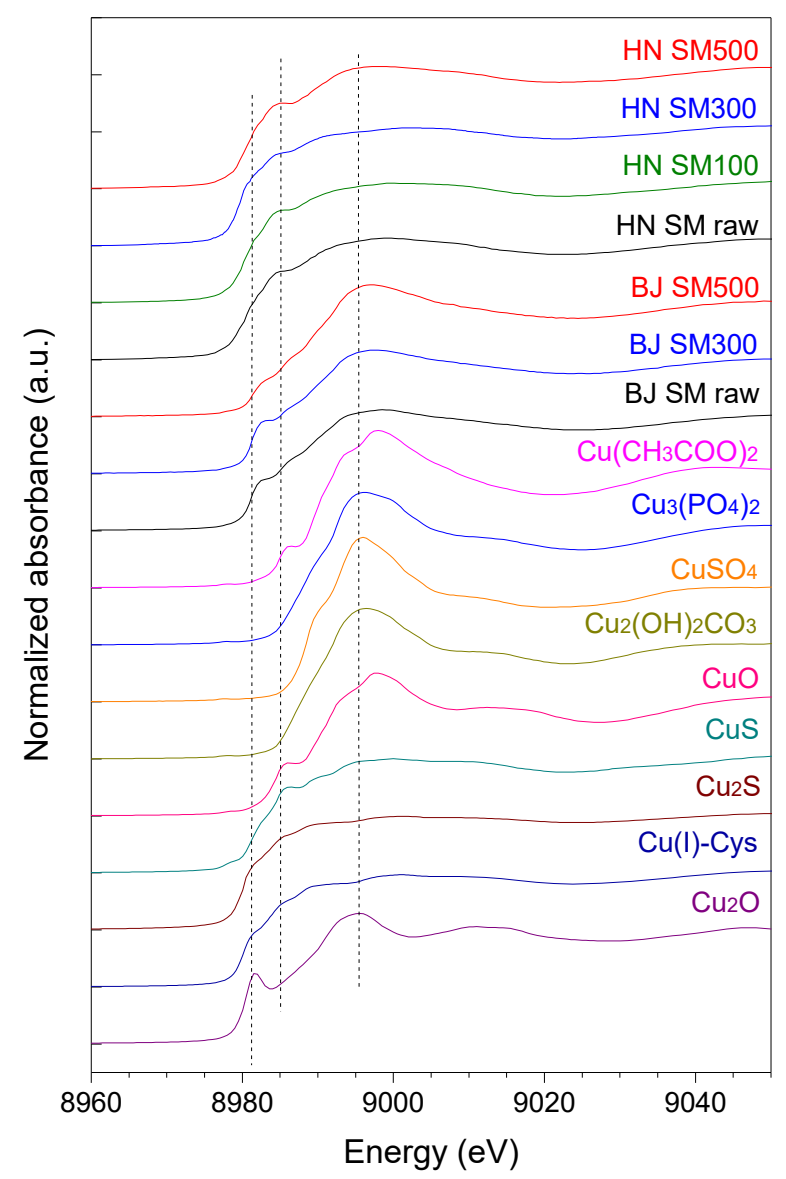

Figure S1. $\mathrm{Cu} K$-edge XANES spectra of raw swine manures from Henan (HN) and Beijing (BJ) swine farms and their biochar samples as well as the relevant reference compounds.
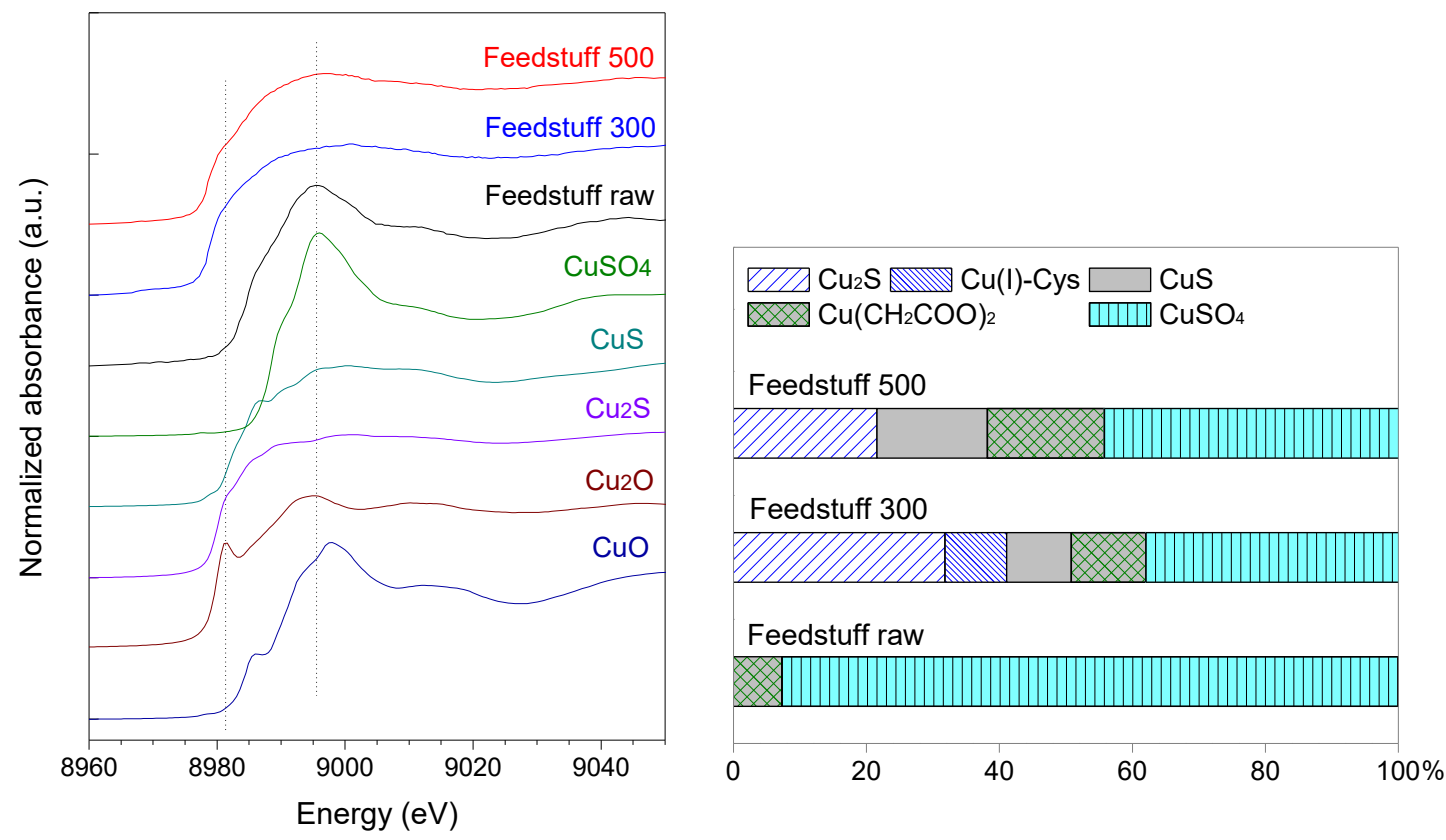

Figure S2. Cu $K$-edge XANES spectra of raw feedstuff and derived biochar samples and the species distribution of $\mathrm{Cu}$ in the samples based on LCF of the XANES spectra. 

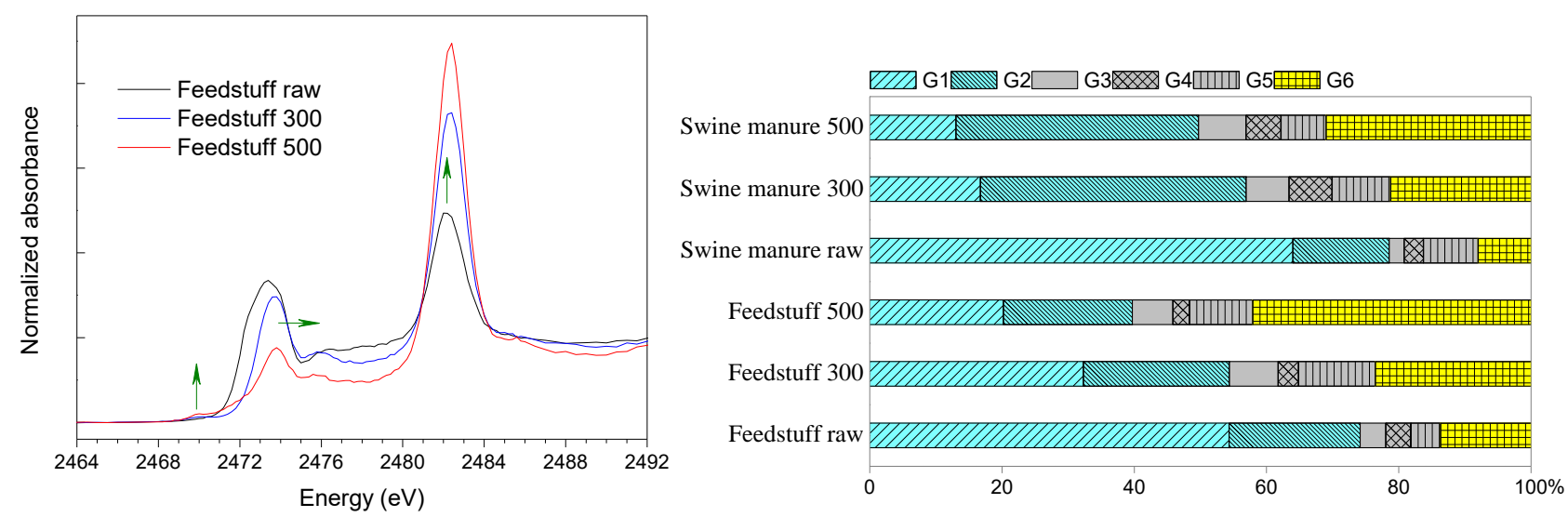

Figure S3. Sulfur $K$-edge XANES spectra of feedstuff and derived biochar, and the percentage (\%) of reduced (G1 and G2), intermediate (G3, G4 and G5), and oxidized (G6) S fractions in the swine manure and feedstuff samples, as calculated by spectral deconvolution by Gaussian curve fitting and subsequently corrected for absorption cross-section from $\mathrm{S} K$-edge XANES spectra (Luo et al., 2014).

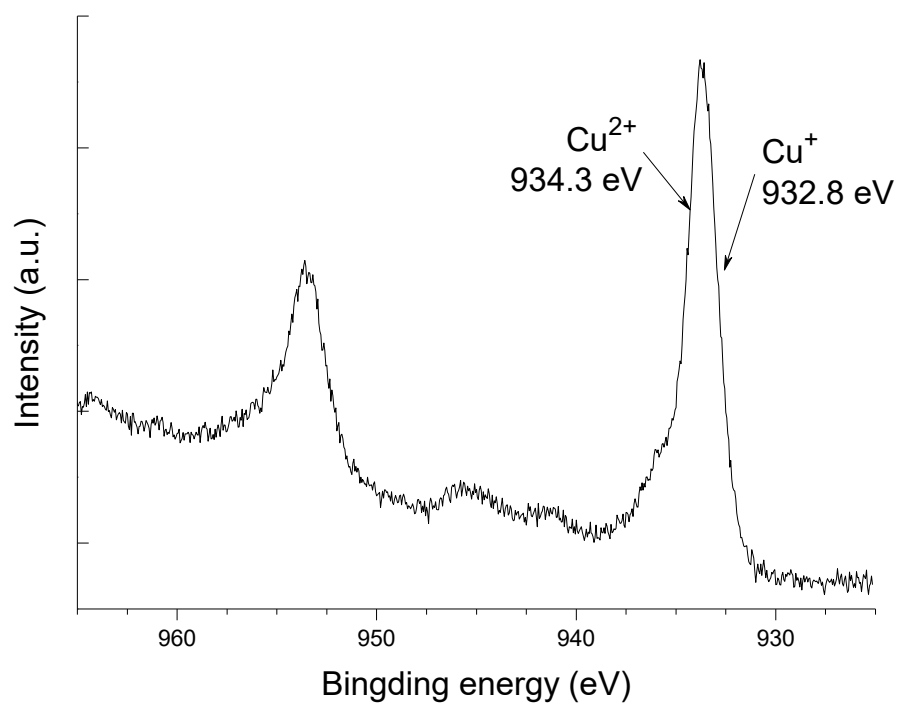

Figure S4. Cu2p X-ray photoelectron spectroscopy spectrum revealed $\mathrm{Cu}^{2+}$ was quickly reduced into $\mathrm{Cu}^{+}$in the presence of cysteine within $1 \mathrm{~h}$. 

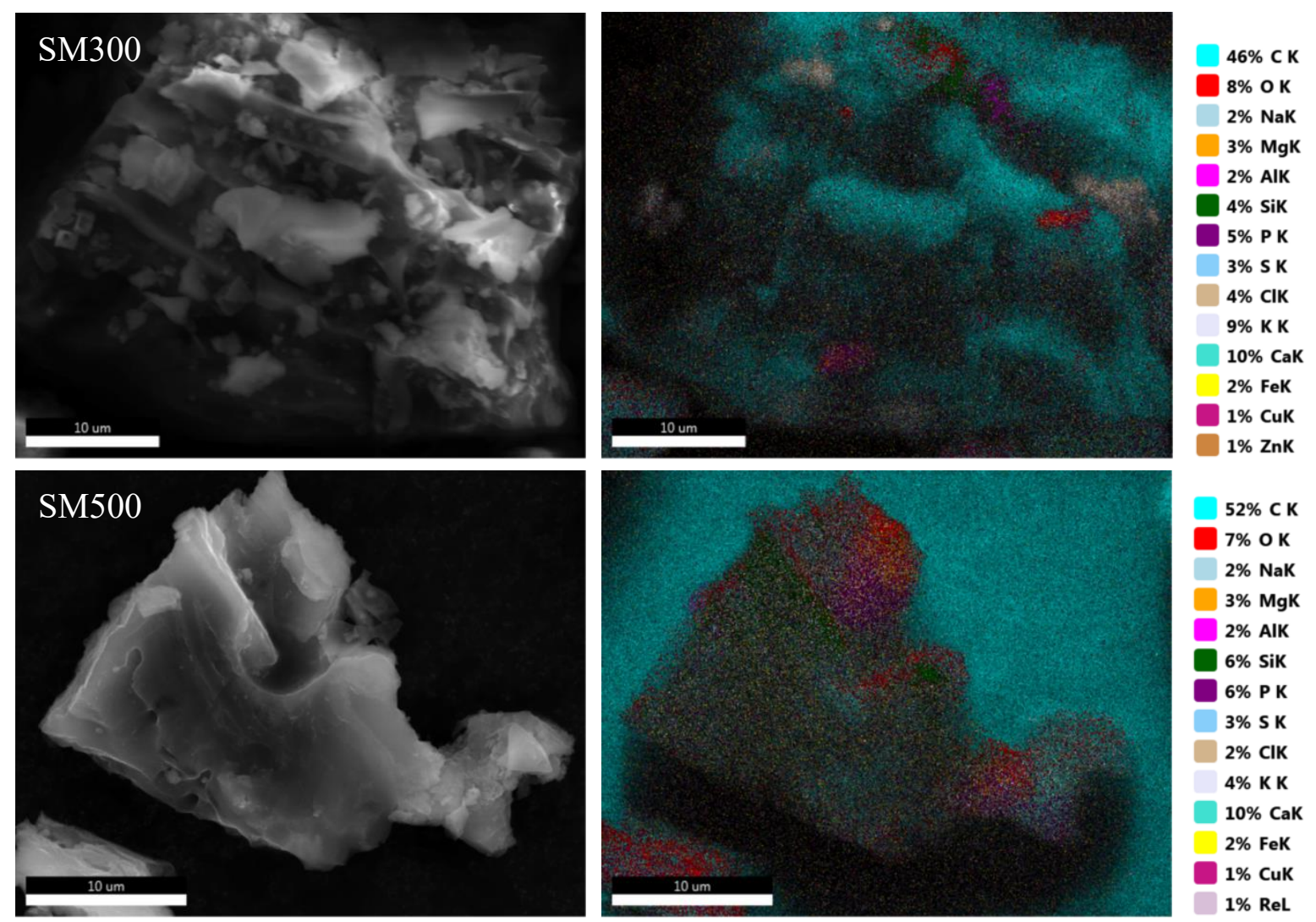

Figure S5. SEM-EDS analysis showing the elemental distribution in swine manure-derived biochar (SM300 and SM500) samples.

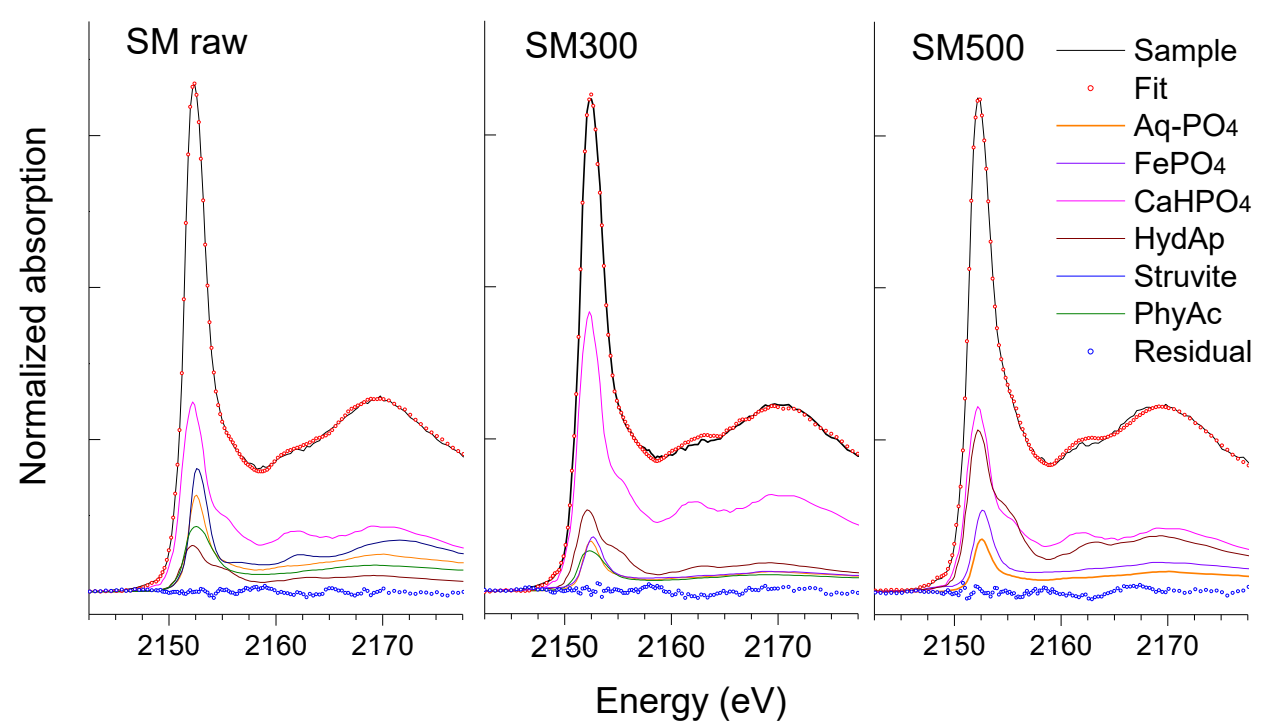

Figure S6. P $K$-edge XANES spectra of swine manure (SM raw) and derived biochar (SM300 and SM500) samples and LCF results. 


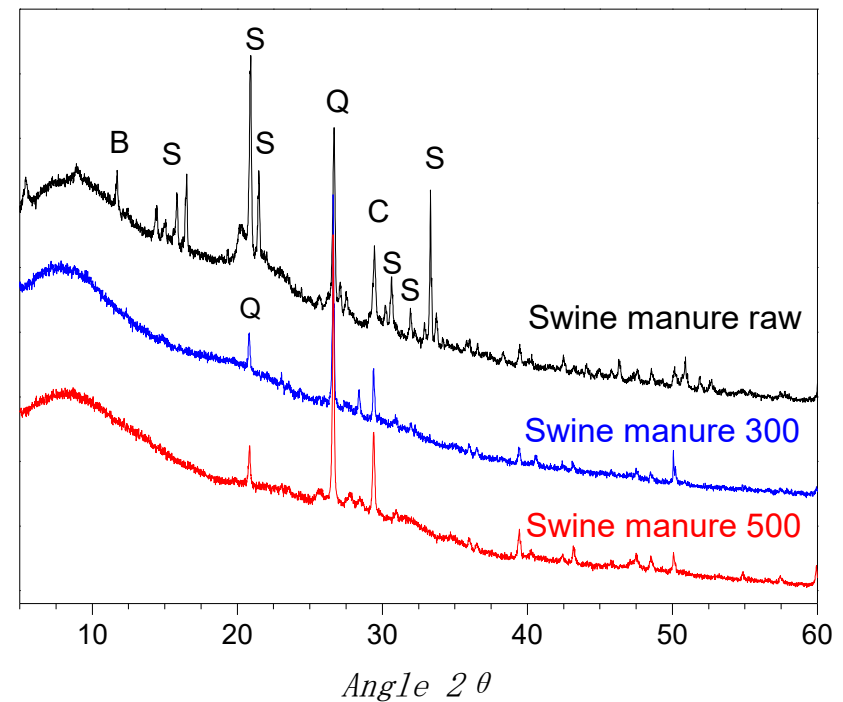

Figure S7. X-ray powder diffractograms of swine manure and derived biochar samples (S, Struvite; B, Brushite; C, Calcite; Q, Quartz).

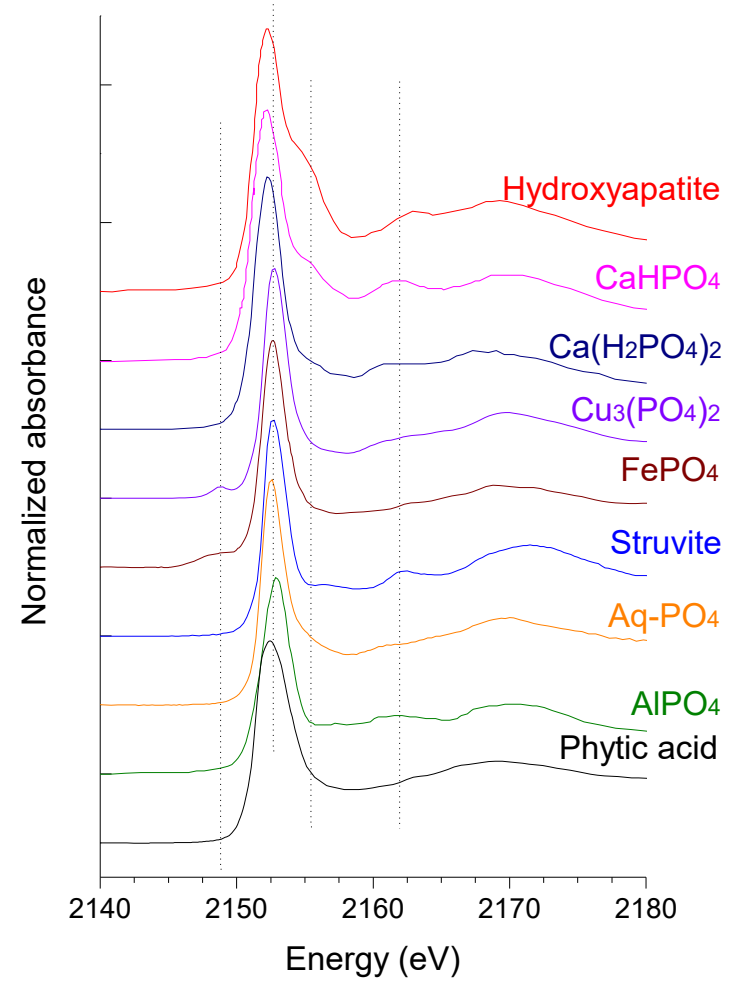

Figure S8. Phosphorus $K$-edge XANES spectra of selected standards. 
Table S1. Selected properties of feedstuff (FS) from a Henan swine farm and swine manure (SM) from a Beijing swine farm and their derived biochars

\begin{tabular}{llllll}
\hline \multirow{2}{*}{ Sample } & Total $\mathrm{Cu}$ & $\begin{array}{l}\text { Available } \\
\mathrm{Cu}\end{array}$ & Total S & Total $\mathrm{P}$ & Available P \\
& $\mathrm{mg} / \mathrm{kg}$ & $\mathrm{mg} / \mathrm{kg}$ & $\mathrm{g} / \mathrm{kg}$ & $\mathrm{g} / \mathrm{kg}$ & $\mathrm{mg} / \mathrm{kg}$ \\
FS raw & $448.9(10.6)^{\mathrm{a}}$ & $28.3(1.3)$ & $5.8(0.4)$ & $11.7(0.3)$ & $1880.0(46.2)$ \\
FS300 & $683.5(9.7)$ & $3.2(0.2)$ & $4.9(0.2)$ & $14.6(0.3)$ & $690.6(25.1)$ \\
FS500 & $764.7(14.1)$ & $44.3(3.5)$ & $5.3(0.2)$ & $17.5(0.2)$ & $2146.8(72.6)$ \\
SM raw & $153.2(3.8)$ & $72.6(2.2)$ & $6.6(0.2)$ & $12.5(0.2)$ & $1909.7(24.6)$ \\
SM300 & $226.2(6.1)$ & $9.4(0.7)$ & $5.9(0.1)$ & $16.7(0.2)$ & $138.6(3.3)$ \\
SM500 & $304.3(4.2)$ & $23.5(0.9)$ & $6.3(0.3)$ & $18.2(0.4)$ & $1986.8(27.2)$ \\
\hline
\end{tabular}

${ }^{a}$ Values in brackets show standard error.

Table S2. Copper speciation distribution (\%) in swine manure from a Henan swine farm and derived biochars based on LCF of $\mathrm{Cu} K$-edge EXAFS spectra

\begin{tabular}{llrlrrr}
\hline Sample & $\mathrm{Cu}_{2} \mathrm{~S}$ & $\mathrm{Cu}(\mathrm{I})-\mathrm{Cys}$ & $\mathrm{CuS}$ & $\mathrm{Cu}\left(\mathrm{CH}_{3} \mathrm{COO}\right)_{2}$ & $\mathrm{CuSO}_{4}$ & $R$-factor \\
SM raw & $61.9(7.6)^{\mathrm{a}}$ & $21.0(5.3)$ & & $7.2(3.1)$ & $9.9(2.2)$ & 0.153 \\
$\mathrm{SM} 100$ & $41.2(6.9)$ & $25.6(1.6)$ & $15.4(2.2)$ & $17.8(2.0)$ & & 0.217 \\
$\mathrm{SM} 300$ & $64.8(10.1)$ & $10.3(2.3)$ & $9.7(0.9)$ & $15.2(4.0)$ & & 0.326 \\
SM500 & $27.3(7.7)$ & & $28.4(2.7)$ & $12.8(2.6)$ & $31.5(8.9)$ & 0.267 \\
\hline
\end{tabular}

${ }^{\text {a }}$ Values in brackets show the percentage variation in the calculated values. Goodness of fit is indicated by $R$-factor.

Table S3. Phosphorus speciation distribution (\%) in swine manure from a Henan swine farm and derived biochars estimated by LCF of $K$-edge XANES spectra

\begin{tabular}{lccccccc}
\hline Sample & Aq-PO$_{4}$ & $\mathrm{CaHPO}_{4}$ & HydAp & Struvite & $\mathrm{FePO}_{4}$ & Organic P & R-factor \\
SM raw & $19.0(1.7)^{\mathrm{a}}$ & $33.7(0.7)$ & $7.8(0.4)$ & $25.2(0.9)$ & & $14.3(1.2)$ & 0.00326 \\
SW300 & $10.6(1.3)$ & $53.6(2.1)$ & $14.9(0.8)$ & & $11.4(0.4)$ & $9.5(0.7)$ & 0.00511 \\
SW500 & $11.9(1.2)$ & $37.8(1.6)$ & $31.8(1.6)$ & & $18.5(1.0)$ & & 0.00727 \\
\hline
\end{tabular}

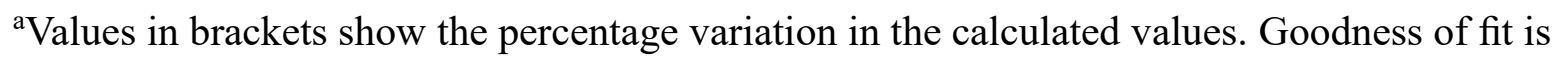
indicated by $R$-factor. HydAp: hydroxyapatite; Struvite: $\mathrm{MgNH}_{4} \mathrm{PO}_{3}$. 


\section{References}

Brunn, S.; Harmer, S. L.; Bekiaris, G.; Christel W.; Zuin L.; Hu Y. F.; Jensen L. S.; Lombi E. The effect of different pyrolysis temperatures on the speciation and availability in soil of $\mathrm{P}$ in biochar produced from the solid fraction of manure. Chemosphere 2017, 169, 377-386.

Donner, E.; Howard, D. L.; de Jonge, M. D.; Paterson, D.; Cheah, M. H.; Naidu, R.; Lombi, E. X-ray absorption and micro X-ray fluorescence spectroscopy investigation of copper and zinc speciation in biosolids. Environ. Sci. Technol. 2011, 45 (17), 7249-7257.

Güngör, K.; Jürgensen, A.; Karthikeyan, K. G. Determination of phosphorus speciation in dairy manure using XRD and XANES spectroscopy. J. Environ. Qual. 2007, 36 (6), 1856-1863.

Ingall, E. D.; Brandes, J. A.; Diaz, J. M.; de Jonge, M. D.; Paterson, D.; McNulty, I.; Elliott, W. C.; Northrup, P. Phosphorus K-edge XANES spectroscopy of mineral standards. J. Synchrotron Radiat. 2011, 18, 189-197.

Lindsay, W. L.; Norvell, W. A. Development of a DTPA soil test for zinc, iron, manganese, and copper. Soil Sci. Soc. Am. J. 1978, 42 (3), 421-428.

Luo, L.; Ma, Y. B.; Sanders, R. L.; Xu, C.; Li, J. M.; Myneni, S. C. B. Speciation and transformation of phosphorus in three long-term fertilized Chinese soils using chemical fractionation and P Kedge XANES spectroscopy. Nutr. Cycl. Agroecosyst. 2017, 107 (2), 215-226.

Luo, L.; Xu, C.; Ma, Y. B.; Zheng, L.; Liu, L. J.; Lv, J. T.; Zhang, S. Z. Sulfur speciation in an arable soil as affected by sample pretreatments and sewage sludge application. Soil Sci. Soc. Am. J. 2014, $78(5), 1615-1623$.

Manceau, A.; Nagy, K. L. Quantitative analysis of sulfur functional groups in natural organic matter by XANES spectroscopy. Geochim. Cosmochim. Acta 2012, 99, 206-223.

Meng, J.; Liang, S. J.; Tao, M. M.; Liu, X. M.; Brookes, P. C.; Xu, J. M. Chemical speciation and risk assessment of $\mathrm{Cu}$ and $\mathrm{Zn}$ in biochars derived from co-pyrolysis of pig manure with rice straw. Chemosphere 2018, 200, 344-350.

Meng, J.; Wang, L.; Zhong, L.; Liu, X. M.; Brooks, P. C.; Xu, J. M. Contrasting effects of composting and pyrolysis on bioavailability and speciation of $\mathrm{Cu}$ and $\mathrm{Zn}$ in pig manure. Chemosphere 2017, 180, 93-99.

Ravel, B.; Newville, M. ATHENA, ARTEMIS, HEPHAESTUS: data analysis for X-ray absorption spectroscopy using IFEFFIT. J. Synchrotron Radiat. 2005, 12, 537-541.

Werner, F.; Prietzel, J. Standard protocol and quality assessment of soil phosphorus speciation by $\mathrm{P}$ K-edge XANES spectroscopy. Environ. Sci. Technol. 2015, 49 (17), 10521-10528. 